\title{
Amycolatopsis australiensis sp. nov., an actinomycete isolated from arid soils
}

\author{
Geok Yuan Annie Tan, ${ }^{1} \dagger$ Stuart Robinson, ${ }^{2}$ Ernest Lacey ${ }^{2}$ \\ and Michael Goodfellow ${ }^{1}$ \\ ${ }^{1}$ Microbial Resources Laboratory, Division of Biology, University of Newcastle, Newcastle upon \\ Tyne NE1 7RU, UK \\ ${ }^{2}$ Microbial Screening Technologies, Building A, 28-54 Percival Road, Smithfield, New South \\ Wales 2164, Australia
}

\begin{abstract}
The taxonomic position of a group of mesophilic actinomycetes isolated from arid Australian soils was determined using a polyphasic approach. The organisms shared chemical and morphological markers typical of members of the genus Amycolatopsis. They had identical 16S rRNA gene sequences and formed a distinct phyletic line in the Amycolatopsis mediterranei clade, being most closely related to $A$. mediterranei. In addition, they shared a range of phenotypic properties that distinguished them from representatives of all of the species classified in this clade. The combined genotypic and phenotypic data indicate that the strains merit species status within the genus Amycolatopsis. The name proposed for the novel species is Amycolatopsis australiensis sp. nov.; the type strain is $\mathrm{GYO}^{\mathrm{T}} \mathrm{8}^{\top}$ ( $\left.=\mathrm{DSM} 44671^{\top}=\mathrm{NCIMB} 14142^{\top}\right)$.
\end{abstract}

The genus Amycolatopsis was proposed by Lechevalier et al. (1986) for aerobic, filamentous actinomycetes that contained meso-diaminopimelic acid, arabinose and galactose (wall chemotype IV sensu Lechevalier \& Lechevalier, 1970), phosphatidylethanolamine as the diagnostic polar lipid (phospholipid type 2 sensu Lechevalier et al., 1977) and diand tetra-hydrogenated menaquinones with nine isoprene units as the predominant isoprenologues, but lacked mycolic acids. The genus currently encompasses 31 species with validly published names, which form a distinct phyletic line within the 16S rRNA gene tree for the Pseudonocardiaceae (Lee, 2006). Amycolatopsis species fall into several multimembered 16S rRNA gene groups, such as the Amycolatopsis methanolica and Amycolatopsis orientalis clades (Kim et al., 2002; Saintpierre-Bonaccio et al., 2005); the type strain of Amycolatopsis fastidiosa forms a single-membered phyletic line at the foot of the Amycolatopsis tree (Goodfellow et al., 2001; Huang et al., 2001, 2004).

Amycolatopsis strains can be distinguished from members of the other genera classified in the family Pseudonocardiaceae by using genus-specific oligonucleotide primers (Tan et al., 2006) and chemical and morphological markers (Kim \& Goodfellow, 1999). Similarly, a range of phenotypic properties are available for the identification of

†Present address: Microbiology Division, Institute of Biological Sciences, University of Malaya, 50603 Kuala Lumpur, Malaysia.

The GenBank/EMBL/DDBJ accession numbers for the 16S rRNA gene sequences of strains GY048', GY049, GY056, GY064, GY269, GY276 and GY286 are AY129753, AY129754, AY129757, AY129759, AY129770, AY129771 and AY129772, respectively.
Amycolatopsis strains (Goodfellow et al., 2001; Wink et al., 2003; Saintpierre-Bonaccio et al., 2005). Members of the genus have been isolated from vegetable matter (Lechevalier et al., 1986) and clinical material (Labeda et al., 2003; Huang et al., 2004) but it is evident from the application of improved selective isolation and characterization procedures that they are common in soil (Tan et al., 2006). Amycolatopsis strains are a rich source of secondary metabolites, including ansamycins (rifamycins and tolypomycins) and glycopeptides (balhimycins and vancomycins). Their commercial significance has led to an intensive search of Amycolatopsis strains for sources of novel pharmaceutical activities - an activity that has promoted a better understanding of the taxonomic structure of the genus (Wink et al., 2003).

The present polyphasic study was designed to establish the taxonomic status of seven Amycolatopsis isolates, of which three, strains GY048 ${ }^{\mathrm{T}}$, GY056 and GY064, form a distinct lineage in the Amycolatopsis 16S rRNA gene tree (Tan et al., 2006). The resultant data show that all of the isolates represent a novel species of the genus Amycolatopsis.

Strains GY048 ${ }^{\mathrm{T}}$, GY049, GY056, GY064, GY269, GY276 and GY286 were isolated on SM2 agar plates that had been inoculated with suspensions of a composite arid Australian soil sample and incubated at $28{ }^{\circ} \mathrm{C}$ for 3 weeks, as described by Tan et al. (2006). The organisms were maintained on modified Bennett's agar slants (Jones, 1949) at room temperature and as suspensions of mycelial fragments in glycerol $(20 \%, \mathrm{v} / \mathrm{v})$ at $-20{ }^{\circ} \mathrm{C}$. Biomass samples for the molecular systematic studies were prepared by growing the 
isolates in glucose/yeast extract broth shake flasks for 3 days at $28{ }^{\circ} \mathrm{C}$. Cultures were checked for purity, killed by shaking with formalin $(1 \%, \mathrm{v} / \mathrm{v})$ and harvested by centrifugation. Cells were washed in $\mathrm{NaCl} / \mathrm{EDTA}$ buffer $(0 \cdot 1 \mathrm{M}$ EDTA, $\mathrm{pH} 8 \cdot 0,0 \cdot 1 \mathrm{M} \mathrm{NaCl})$ and stored at $-20{ }^{\circ} \mathrm{C}$ until needed.

Extraction of chromosomal DNA, PCR amplification and sequencing of $16 \mathrm{~S}$ rRNA genes from isolates GY049, GY269, GY276 and GY286 were achieved using procedures described previously (Kim et al., 2002; Tan et al., 2006). The resultant 16S rRNA gene sequences were aligned manually, using the PHYDIT program (available at http://plaza.snu.ac. $\mathrm{kr} / \sim \mathrm{jchun}$ /phydit/), against corresponding sequences of representatives of genera classified in the family Pseudonocardiaceae (data not shown) and of type species of the genus Amycolatopsis (as retrieved from the GenBank database). Unrooted trees were inferred by using the leastsquares (Fitch \& Margoliash, 1967), maximum-parsimony (Fitch, 1971) and neighbour-joining (Saitou \& Nei, 1987) tree-making algorithms. Evolutionary distance matrices were generated for the least-squares and neighbour-joining algorithms after Jukes \& Cantor (1969). The analyses were carried out using the PHYLIP suite of programs (Felsenstein, 1993) and the topologies of the resultant trees were evaluated by using a bootstrap analysis (Felsenstein, 1985) of the neighbour-joining dataset with the CONSENSE and SEQBOOT programs from the PHYLIP package. The root position of the unrooted Amycolatopsis tree based on the neighbour-joining method was estimated by using Pseudonocardia thermophila ATCC $19285^{\mathrm{T}}$ (GenBank accession no. X53195) as the outgroup.

It is evident from Fig. 1 that the strains tested share identical (100\% similarity) 16S rRNA gene sequences both with each other and with isolates $\mathrm{GY} 048^{\mathrm{T}}$, GY056 and GY064. These strains form a distinct phyletic line within the Amycolatopsis mediterranei clade, a taxon that encompasses the type strains of nine Amycolatopsis species with validly published names; the taxonomic integrity of this clade was supported by the results from all of the tree-making algorithms and by a bootstrap value of $86 \%$ in the neighbourjoining analysis. The isolates showed the highest level of $16 \mathrm{~S}$ rRNA gene similarity with the type strain of A. mediterranei (98.6\%, a value that corresponded to 20 nucleotide differences at 1411 locations). Relatively high similarity values were shown with the type strains of Amycolatopsis balhimycina (97.8\%), Amycolatopsis kentuckyensis (98.2\%), Amycolatopsis lexingtonensis $(98 \cdot 0 \%)$, Amycolatopsis plumensis

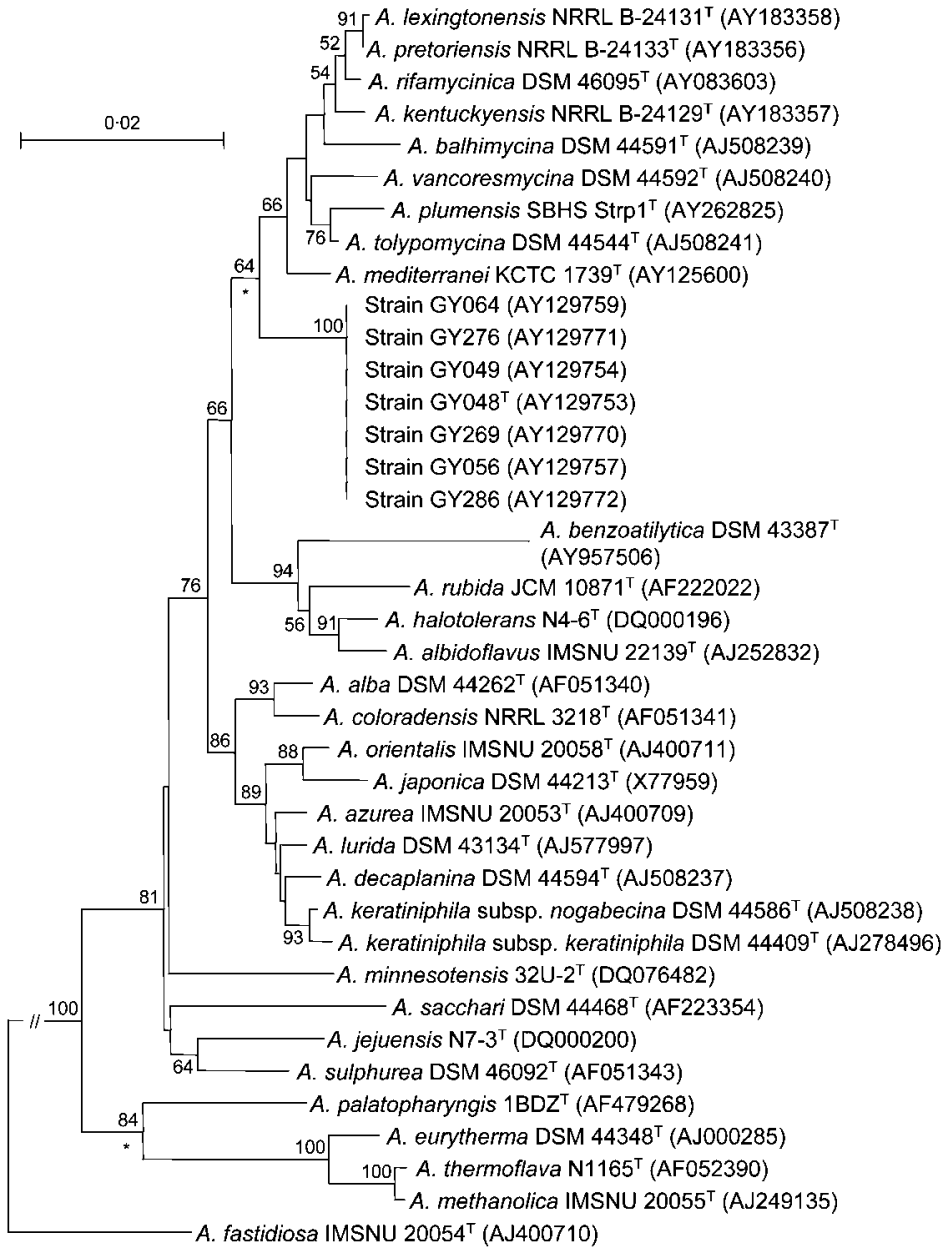

Fig. 1. Neighbour-joining (Saitou \& Nei, 1987) phylogenetic tree, based on almostcomplete 16S rRNA gene sequences $(\geqslant 1460 \mathrm{nt})$, showing the relationships between the novel strains and representatives of the genus Amycolatopsis. Asterisks indicate branches of the tree that were also found using the least-squares (Fitch \& Margoliash, 1967) and maximum-parsimony (Fitch, 1971) tree-making algorithms. Numbers at nodes indicate levels of bootstrap support (\%) based on a neighbour-joining analysis of 1000 resampled datasets. Bar, 0.02 substitutions per nucleotide position. 
(98.0 \%), Amycolatopsis pretoriensis (98.2\%), Amycolatopsis rifamycinica (98.2\%), Amycolatopsis tolypomycina (98.5\%) and Amycolatopsis vancoresmycina $(98 \cdot 1 \%)$.

DNA-DNA relatedness studies were not carried out between isolate $\mathrm{GY} 048^{\mathrm{T}}$ and its closest phylogenetic neighbours, as some of the latter have almost identical 16S rRNA gene similarity values but show DNA-DNA hybridization scores well below the $70 \%$ cut-off point recommended by Wayne et al. (1987) for the circumscription of strains that belong to the same genomic species. The type strains of $A$. lexingtonensis and A. pretoriensis, for example, share a $16 \mathrm{~S}$ rRNA gene similarity of $99.9 \%$ and a DNA-DNA relatedness value of $54 \cdot 1 \%$ (Labeda et al., 2003). Similarly, the type strain of $A$. rifamycinica has only six mismatches (99.6\% similarity) with respect to its closest neighbour, $A$. kentuckyensis, but shows a DNA-DNA hybridization value of only $67 \%$ with the latter (Bala et al., 2004).

Isolate $\mathrm{GY} 048^{\mathrm{T}}$ was examined for key chemical markers to determine whether it had a chemical profile consistent with its classification in the genus Amycolatopsis. Biomass for the chemotaxonomic studies was prepared by growing the isolate in glucose/yeast extract broth shake flasks (150 r.p.m.) for 3 days at $28^{\circ} \mathrm{C}$; the cells were washed in distilled water and then freeze-dried. Standard HPLC and TLC procedures were used to determine the predominant menaquinones (Collins, 1994), the type of muramic acid residue (Uchida et al., 1999), the major polar lipids (Minnikin et al., 1984) and the predominant wholeorganism sugars (Schaal, 1985) of strain $\mathrm{GY} 048^{\mathrm{T}}$. The control organisms were A. orientalis KCTC $9412^{\mathrm{T}}$, Gordonia bronchialis $\mathrm{N}_{65} 4^{\mathrm{T}}$ and Nocardia brasiliensis $\mathrm{N} 318^{\mathrm{T}}$.

Strain GY048 ${ }^{\mathrm{T}}$, which is known to contain meso-diaminopimelic acid but which lacks mycolic acids (Tan et al., 2006), contained arabinose and galactose in whole-organism hydrolysates, contained $\mathrm{N}$-acetylated muramic acid, possessed diphosphatidylglycerol, phosphatidylethanolamine, phosphatidylglycerol, phosphatidylinositol and phosphatidylmethylethanolamine as the major polar lipids (phospholipid pattern type 2 sensu Lechevalier et al., 1977) and contained tetrahydrogenated menaquinone with nine isoprene units $\left[\mathrm{MK}-9\left(\mathrm{H}_{4}\right)\right]$ as the predominant isoprenologue (66\% of the total menaquinone composition) and smaller proportions of MK- $8\left(\mathrm{H}_{2}\right)$ (26\% of the total) and MK- $9\left(\mathrm{H}_{6}\right)$ ( $8 \%$ of the total). These chemical markers serve to distinguish strain $\mathrm{GY} 048^{\mathrm{T}}$ from all other actinomycetes with wall chemotype IV, apart from those classified in the genus Amycolatopsis (Lechevalier et al., 1986; Embley et al., 1988; Yassin et al., 1991, 1993; Kim \& Goodfellow, 1999).

Crude extracts of the isolates were prepared by methanol extraction of agar cultures grown on modified Bennett's agar (Jones, 1949) and yeast extract-malt extract agar (ISP 2; Shirling \& Gottlieb, 1966) at $28{ }^{\circ} \mathrm{C}$ for 7 days. Antibacterial and anti-yeast activities were assessed using Bacillus subtilis ATCC 6633 and Saccharomyces cerevisiae ATCC 9763, respectively. All strains produced extracts that exhibited low titres of antibacterial or anti-yeast activity when grown on either medium.

The morphological properties of the isolates were observed, using a Nikon Optiphot light microscope fitted with a longworking-distance objective, after growth on modified Bennett's agar (Jones, 1949) supplemented with mannitol $(0.5 \%, \mathrm{w} / \mathrm{v})$ and soybean flour $(0.5 \%, \mathrm{w} / \mathrm{v})$, and after growth on tyrosine agar (ISP 7; Shirling \& Gottlieb, 1966) for 14 days at $28^{\circ} \mathrm{C}$. In addition, a range of phenotypic tests were carried out using media and methods described previously (de Boer et al., 1990; Goodfellow et al., 1997, 2001). The strains shared a combination of phenotypic properties that serve to distinguish them from the type strains of Amycolatopsis species classified in the A. mediterranei clade (Table 1).

It is evident from the genotypic and phenotypic data that the seven isolates form a homogeneous taxon that can be distinguished from representatives of all of the Amycolatopsis species with validly published names. This taxon should be recognized as a novel Amycolatopsis species, for which the name Amycolatopsis australiensis sp. nov. is proposed.

\section{Description of Amycolatopsis australiensis sp. nov.}

Amycolatopsis australiensis (aus.tra.li.en'sis. N.L. fem. adj. australiensis pertaining to Australia, the source of the soil from which the first strains were isolated).

Aerobic, Gram-positive, non-acid-alcohol-fast, non-motile actinobacteria that form extensively branched substrate mycelia that fragment into squarish, rod-shaped elements. Abundant, white aerial hyphae and pale-yellow substrate mycelia are formed on modified Bennett's agar supplemented with mannitol and soybean flour; a medium-yellow diffusible pigment is evident on this medium. Melanin pigments are not produced on peptone-yeast extractiron or tyrosine agars. Good growth occurs between 28 and $45^{\circ} \mathrm{C}$, and from $\mathrm{pH} 5$ to 7 . Nitrate is reduced to nitrite; elastin, Tween 40 and uric acid are degraded. $\mathrm{D}(+)$-Arabitol, $\mathrm{D}(+)$-cellobiose, dextrin, $\mathrm{D}(+)$-galactose, $\mathrm{D}(+)$-glucose, glycerol, glycogen, myo-inositol, $\alpha$-lactose, $\mathrm{D}(+)$-maltose, $\mathrm{D}(+)$-mannitol, $\mathrm{D}(+)$-melezitose, $\mathrm{D}(+)$ raffinose, sucrose, $\mathrm{D}(+)$-trehalose, xylitol, $\mathrm{D}(+)$-xylose (all at $1 \%, \mathrm{w} / \mathrm{v}$ ) and citric acid, oxalic acid and propionic acid (all at $0 \cdot 1 \%, \mathrm{w} / \mathrm{v}$ ) are used as sole carbon sources, but adonitol, meso-erythritol, $\mathrm{D}(+)$-melibiose, methyl $\alpha$-D-glucoside, $\mathrm{D}(+)$-ribose, $\mathrm{D}(-)$-sorbitol (all at $1 \%$, $\mathrm{w} / \mathrm{v}$ ) and sodium benzoate, sodium lactate and sodium mucate (at $0 \cdot 1 \%, \mathrm{w} / \mathrm{v})$ are not. Acid is formed from $\mathrm{D}(+)$-arabitol, $\mathrm{D}(+)$-glucose, glycerol, glycogen, $\mathrm{D}(+)$ mannose and $\mathrm{D}(+)$-turanose, but not from dulcitol, $\mathrm{D}(+)$-ribose or xylitol. The organism is sensitive to novobiocin $\left(10 \mu \mathrm{g} \mathrm{ml}^{-1}\right)$, penicillin $\mathrm{G}\left(20 \mu \mathrm{g} \mathrm{ml}^{-1}\right)$, rifampicin $\left(10 \mu \mathrm{g} \mathrm{ml}^{-1}\right)$ and streptomycin sulphate $\left(16 \mu \mathrm{g} \mathrm{ml}^{-1}\right)$, but resistant to gentamicin sulphate $\left(5 \mu \mathrm{g} \mathrm{ml}^{-1}\right)$, neomycin 
Table 1. Characteristics that separate the novel strains from representatives of Amycolatopsis species classified in the $A$. mediterranei 16S rRNA gene clade

Strains: 1, strains GY048 ${ }^{\mathrm{T}}$, GY049, GY056, GY064, GY269, GY276 and GY286 (number of strains testing positive is given); 2, A. balhimycina DSM $44591^{\mathrm{T}}$; 3, A. kentuckyensis NRRL B-24129 $; 4$, A. lexingtonensis NRRL B-24131 ${ }^{\mathrm{T}}$; 5, A. mediterranei DSM $13685^{\mathrm{T}}$; 6 , A. orientalis IMSNU $20058^{\mathrm{T}} ; 7$, A. plumensis DSM $44776^{\mathrm{T}} ; 8$, A. pretoriensis NRRL B-24133 ${ }^{\mathrm{T}}$; 9, A. rifamycinica DSM 46095 ${ }^{\mathrm{T}}$; 10 , A. tolypomycina DSM $44544^{\mathrm{T}}$; 11, A. vancoresmycina DSM $44592^{\mathrm{T}}$. Data for type strains were taken from Bala et al. (2004), Kim et al. (2002), Labeda et al. (2003), Saintpierre-Bonaccio et al. (2005) and Wink et al. (2003). The novel strains gave variable responses to the following tests: acid from dextrin (4 positive), $\mathrm{D}(+)$-maltose (5 positive), $\mathrm{D}(+)$-raffinose ( 3 positive), sucrose (5 positive) and $\mathrm{D}(+)$-trehalose $(4$ positive); decomposition of hypoxanthine ( 5 positive); allantoin hydrolysis (4 positive) and growth at $10^{\circ} \mathrm{C}$ (4 positive). + , Positive; $+\mathrm{W}$, weakly positive; - , negative; ND, no data available.

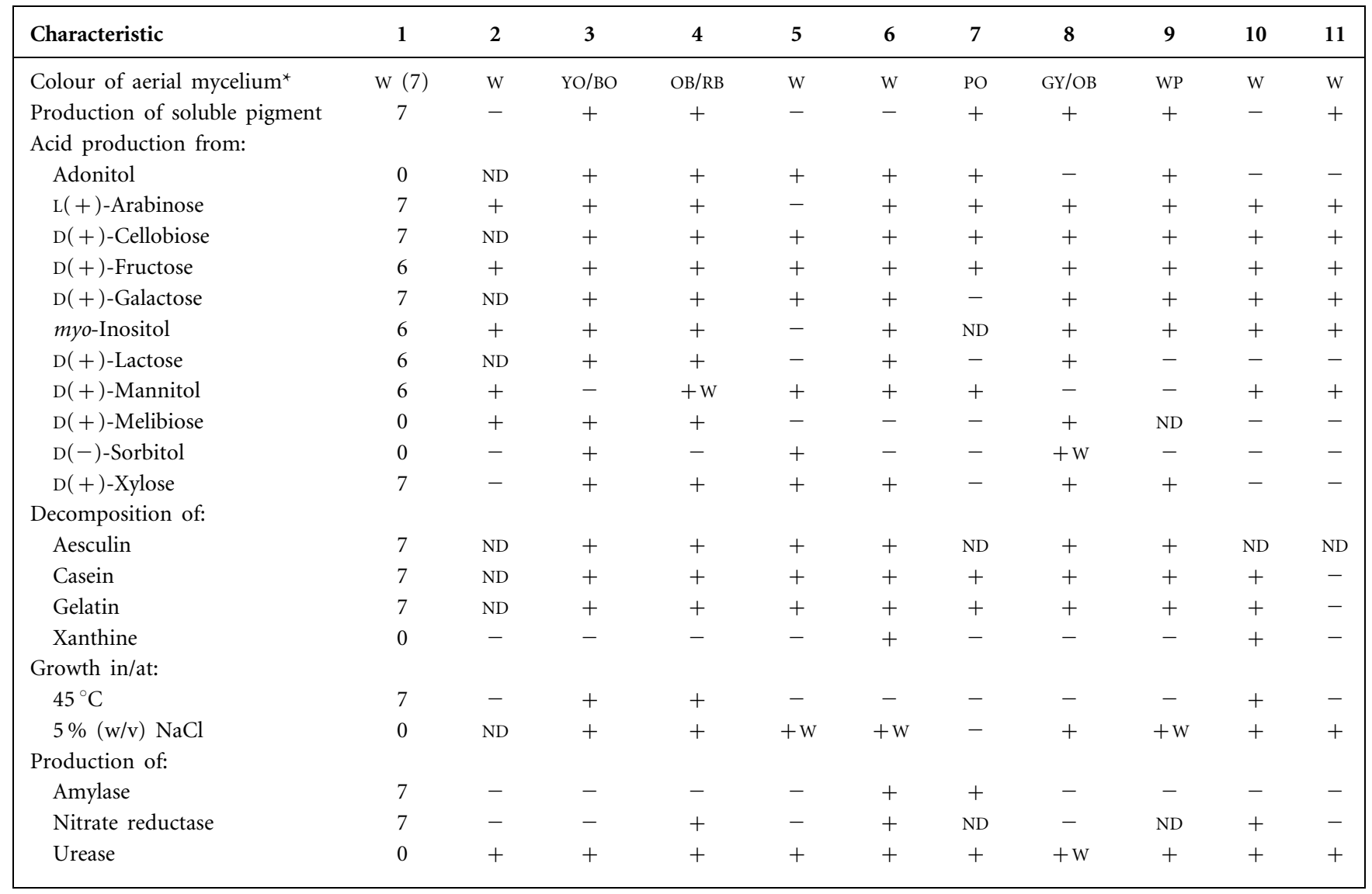

${ }^{\star} \mathrm{BO}$, Brownish orange; GY, greyish yellow; OB, orange-brown; PO, pale orange; RB, reddish brown; w, white; wO, white to olive buff; wP, white to pale pink; YO, yellow-orange.

sulphate $\left(8 \mu \mathrm{g} \mathrm{ml}^{-1}\right)$, polymyxin B sulphate $\left(50 \mu \mathrm{g} \mathrm{ml}^{-1}\right)$ and tobramycin sulphate $\left(8 \mu \mathrm{g} \mathrm{ml}^{-1}\right)$. Activity is shown against B. subtilis ATCC 6633 and S. cerevisiae ATCC 9763 but not against Candida albicans ATCC 10231. Additional phenotypic properties are shown in Table 1.

The type strain, GY048 ${ }^{\mathrm{T}} \quad\left(=\mathrm{DSM} \quad 44671^{\mathrm{T}}=\mathrm{NCIMB}\right.$ $\left.14142^{\mathrm{T}}\right)$, was isolated from arid Australian soils.

\section{Acknowledgements}

G. Y.A.T. gratefully acknowledges receipt of an Overseas Research Scholarship Award, an International Research Bursary (University of Newcastle upon Tyne) and a Departmental Research Studentship
(Division of Biology, University of Newcastle upon Tyne). This work was supported by EC grant QLK3-CT-2001-01783. The authors are indebted to Professor M. A. Barton (University of Adelaide) for providing the soil samples.

\section{References}

Bala, S., Khanna, R., Dadhwal, M., Prabagaran, S. R., Shivaji, S., Cullum, J. \& Lal, R. (2004). Reclassification of Amycolatopsis mediterranei DSM 46095 as Amycolatopsis rifamycinica sp. nov. Int J Syst Evol Microbiol 54, 1145-1149.

Collins, M. D. (1994). Isoprenoid quinones. In Chemical Methods in Prokaryotic Systematics, pp. 265-309. Edited by M. Goodfellow \& A. G. O'Donnell. Chichester: Wiley. 
de Boer, L., Dijkhuizen, L., Grobben, G., Goodfellow, M., Stackebrandt, E., Parlett, J. H., Whitehead, D. \& Witt, D. (1990). Amycolatopsis methanolica sp. nov., a facultatively methylotrophic actinomycete. Int J Syst Bacteriol 40, 194-204.

Embley, T. M., O’Donnell, A. G., Rostron, J. \& Goodfellow, M. (1988). Chemotaxonomy of wall type-IV actinomycetes which lack mycolic acids. J Gen Microbiol 134, 953-960.

Felsenstein, J. (1985). Confidence limits on phylogeny: an appropriate use of the bootstrap. Evolution 39, 783-791.

Felsenstein, J. (1993). PHYLIP (phylogeny inference package), version 3.5.1. http://evolution.genetics.washington.edu/phylip/

Fitch, W. M. (1971). Towards defining the course of evolution: minimum change for a specific tree topology. Syst Zool 20, 406-416.

Fitch, W. M. \& Margoliash, E. (1967). Construction of phylogenetic trees: a method based on mutation distances as estimated from cytochrome $c$ sequences is of general applicability. Science 155, 279-284.

Goodfellow, M., Brown, A. B., Cai, J. P., Chun, J. S. \& Collins, M. D. (1997). Amycolatopsis japonicum sp. nov., an actinomycete producing $(S, S)-N, N^{\prime}$-ethylenediaminedisuccinic acid. Syst Appl Microbiol 20, 78-84.

Goodfellow, M., Kim, S. B., Minnikin, D. E., Whitehead, D., Zhou, Z. H. \& Mattinson-Rose, A. D. (2001). Amycolatopsis sacchari sp. nov., a moderately thermophilic actinomycete isolated from vegetable matter. Int J Syst Evol Microbiol 51, 187-193.

Huang, Y., Qi, W. H., Lu, Z. T., Liu, Z. H. \& Goodfellow, M. (2001). Amycolatopsis rubida sp. nov., a new Amycolatopsis species from soil. Int J Syst Evol Microbiol 51, 1093-1097.

Huang, Y., Pasciak, M., Liu, Z. H., Xie, Q. \& Gamian, A. (2004). Amycolatopsis palatopharyngis sp. nov., a potentially pathogenic actinomycete isolated from a human clinical source. Int J Syst Evol Microbiol 54, 359-363.

Jones, K. L. (1949). Fresh isolates of actinomycetes in which the presence of sporogenous aerial mycelia is a fluctuating characteristic. J Bacteriol 57, 141-145.

Jukes, T. H. \& Cantor, C. R. (1969). Evolution of protein molecules. In Mammalian Protein Metabolism, pp. 21-132. Edited by H. N. Munro. New York: Academic Press.

Kim, S. B. \& Goodfellow, M. (1999). Reclassification of Amycolatopsis rugosa Lechevalier et al. 1986 as Prauserella rugosa gen. nov., comb. nov. Int J Syst Bacteriol 49, 507-512.

Kim, B., Sahin, N., Tan, G. Y. A., Zakrzewska-Czerwinska, J. \& Goodfellow, M. (2002). Amycolatopsis eurytherma sp. nov., a thermophilic actinomycete isolated from soil. Int J Syst Evol Microbiol 52, 889-894.

Labeda, D. P., Donahue, J. M., Williams, N. M., Sells, S. F. \& Henton, M. M. (2003). Amycolatopsis kentuckyensis sp. nov., Amycolatopsis lexingtonensis sp. nov. and Amycolatopsis pretoriensis sp. nov., isolated from equine placentas. Int J Syst Evol Microbiol 53, 1601-1605.

Lechevalier, M. P. \& Lechevalier, H. A. (1970). Chemical composition as a criterion in the classification of aerobic actinomycetes. Int J Syst Bacteriol 20, 435-443.
Lechevalier, M. P., De Bièvre, C. \& Lechevalier, H. A. (1977). Chemotaxonomy of aerobic actinomycetes: phospholipid composition. Biochem Syst Ecol 5, 249-260.

Lechevalier, M. P., Prauser, H., Labeda, D. P. \& Ruan, J. S. (1986). Two new genera of nocardioform actinomycetes - Amycolata gen. nov. and Amycolatopsis gen. nov. Int J Syst Bacteriol 36, 29-37.

Lee, S. D. (2006). Amycolatopsis jejuensis sp. nov. and Amycolatopsis halotolerans sp. nov., novel actinomycetes isolated from a natural cave. Int J Syst Evol Microbiol 56, 549-553.

Minnikin, D. E., O'Donnell, A. G., Goodfellow, M., Alderson, G., Athalye, M., Schaal, A. \& Parlett, J. H. (1984). An integrated procedure for the extraction of bacterial isoprenoid quinones and polar lipids. J Microbiol Methods 2, 233-241.

Saintpierre-Bonaccio, D., Amir, H., Pineau, R., Tan, G. Y. A. \& Goodfellow, M. (2005). Amycolatopsis plumensis sp. nov., a novel bioactive actinomycete isolated from a New-Caledonian brown hypermagnesian ultramafic soil. Int J Syst Evol Microbiol 55, 2057-2061.

Saitou, N. \& Nei, M. (1987). The neighbor-joining method: a new method for constructing phylogenetic trees. Mol Biol Evol 4, 406-425.

Schaal, K. P. (1985). Identification of clinically significant actinomycetes and related bacteria using chemical techniques. In Chemical Methods in Bacterial Systematics, pp. 359-381. Edited by M. Goodfellow \& D. E. Minnikin. London: Academic Press.

Shirling, E. B. \& Gottlieb, D. (1966). Methods for characterization of Streptomyces species. Int J Syst Bacteriol 16, 313-340.

Tan, G. Y. A., Ward, A. C. \& Goodfellow, M. (2006). Exploration of Amycolatopsis diversity in soil using genus-specific primers and novel selective media. Syst Appl Microbiol (in press).

Uchida, K., Kudo, T., Suzuki, K. \& Nakase, T. (1999). A new rapid method of glycolate test by diethyl ether extraction, which is applicable to a small amount of bacterial cells of less than one milligram. J Gen Appl Microbiol 45, 49-56.

Wayne, L. G., Brenner, D. J., Colwell, R. R. \& 9 other authors (1987). International Committee on Systematic Bacteriology. Report of the ad hoc committee on the reconciliation of approaches to bacterial systematics. Int J Syst Bacteriol 37, 463-464.

Wink, J. M., Kroppenstedt, R. M., Ganguli, B. N., Nadkarni, S. R., Schumann, P., Seibert, G. \& Stackebrandt, E. (2003). Three new antibiotic producing species of the genus Amycolatopsis, Amycolatopsis balhimycina sp. nov., A. tolypomycina sp. nov., A. vancoresmycina sp. nov., and description of Amycolatopsis keratiniphila subsp. keratiniphila subsp. nov. and A. keratiniphila subsp. nogabecina subsp. nov. Syst Appl Microbiol 26, 38-46.

Yassin, A. F., Schaal, K. P., Brzezinka, H., Goodfellow, M. \& Pulverer, G. (1991). Menaquinone patterns of Amycolatopsis species. Zentralbl Bakteriol 274, 465-470.

Yassin, A. F., Haggenei, B., Budzikiewicz, H. \& Schaal, K. P. (1993). Fatty acid and polar lipid composition of the genus Amycolatopsis: application of fast atom bombardment-mass spectrometry to structure analysis of underivatized phospholipids. Int J Syst Bacteriol 43, 414-420. 